\section{REPRESENTAÇÕES FEMININAS EM FESTAS DANÇANTES EM ARACAJU NO INÍCIO DO SÉCULO XX: EDUCAÇÃO E SOCIABILIDADE}

\author{
FEMALE REPRESENTATIONS IN DANCE PARTIES IN ARACAJU IN THE EARLY \\ 20 $0^{\text {th }}$ CENTURY: EDUCATION AND SOCIABILITY
}

\begin{abstract}
REPRESENTACIONES FEMENINAS EN CLUBES DE BAILE EN ARACAJU A PRINCIPIOS DEL SIGLO XX: EDUCACIÓN Y SOCIABILIDAD
\end{abstract}

Marlaine Lopes de Almeida*, Coriolano Pereira da Rocha Junior**
Palavras chave:

Educação.

Sociabilidade.

Mulher.

Resumo: 0 presente trabalho tem por objetivo analisar como a educação constituiu-se em um elemento de sociabilidade e condição de acesso do público feminino aos clubes dançantes em Aracaju no início do século XX. O estudo tem como base os pressupostos teóricos e metodológicos da Nova História. Para a fundamentação teórica, nos valemos da categoria de Representação de Roger Chartier (1990) e do conceito de Elites Culturais de Sirinelli (1997). O estudo nos permitiu compreender o uso que as mulheres fizeram da sua formação para frequentarem espaços de sociabilidade, como os bailes dançantes, lugares dotados de significados, ambientes pensados e projetados para constituir momentos de lazer, entretenimento e expressividade cultural e intelectual para algumas mulheres em Aracaju nas primeiras décadas do século XX.

\begin{abstract}
This study aims at examining how education became an element of sociability and a requirement for women to gain access to dance clubs in Aracaju in the early $20^{\text {th }}$ century. The study is based on New History's theoretical and methodological assumptions. For the theoretical foundation, we followed Roger Chartier's (1990) category of Representation and Sirinelli's (1997) concept of Cultural Elites. This study allowed us to understand how women took advantage of their academic qualification in order to attend sociability spaces such as ballrooms, which were places full of meanings and environments thought and designed to provide leisure, entertainment and cultural and intellectual expression for some women in local society.
\end{abstract}

Palabras clave:

Educación.

Sociabilidad.

Mujer.
Resumen: Este trabajo tiene como objetivo analizar cómo la educación se constituyó en un elemento de sociabilidad y en condición de acceso del público femenino a los clubes de baile en Aracaju a principios del siglo XX. El estudio se basa en supuestos teóricos y metodológicos de la Nueva Historia. Para darle fundamento teórico, nos valemos de la categoría de Representación de Roger Chartier (1990) y del concepto de Élites Culturales de Sirinelli (1997). El estudio nos permitió comprender el uso que las mujeres han hecho de su formación para frecuentar los espacios de sociabilidad, como los bailes, lugares dotados de significados, ambientes pensados y diseñados para proporcionar el ocio, el entretenimiento y la expresión cultural e intelectual a algunas mujeres en Aracaju en las primeras décadas del siglo XX.
*Instituto Federal de Educação, Ciência e Tecnologia da Bahia. Irecê, BA, Brasil. E-mail: marla_lopesalmeida@yahoo. com.br

**Universidade Federal da Bahia. Salvador, BA, Brasil.

E-mail: coriolanojunior@uol.com.br

Recebido em: 17-03-2017 Aprovado em: 11-06-2017

(c) (1) (8) Licence 


\section{INTRODUÇÃO}

Este estudo teve como tema a relação entre educação, modos de sociabilidade e a presença das mulheres em espaços públicos. Seu objetivo foi analisar como a educação constituiu-se em um elemento de circulação e convivência social e condição de acesso das mulheres aos espaços de dança, os clubes dançantes, em Aracaju/SE, no início do século XX.

Para situar a mulher no âmbito do entretenimento e da diversão nos clubes dançantes, fez-se necessário compreender a posição das "moças de escola" e a importância da posse de diploma para as mulheres, como símbolo de status intelectual, requisito para 0 acesso do público feminino a determinados espaços, destinados à elite cultural em Aracaju, nas duas primeiras décadas do século XX.

À luz do referencial metodológico da Nova História, o estudo teve como base as prerrogativas dos historiadores da Escola dos Analles, conforme visto em Burke (1992). A partir desta metodologia vimos que é possível instrumentalizar-se com os achados, conceitos e categorias, que suportam informações capazes de reconstituir os processos efetivamente vividos. Como fontes utilizamos os jornais que circularam durante o período estudado, arquivados no Instituto Histórico e Geográfico de Sergipe, no Arquivo Público do Estado de Sergipe, na Biblioteca Epifânio Dórea e no Instituto Tobias Barreto de Educação e Cultura. Para a fundamentação teórica, nos valemos da categoria de Representação de Roger Chartier (1990) e do conceito de Elites Culturais de Sirinelli (1997).

Entendemos que o estudo sobre a presença feminina nos espaços de sociabilidade, a partir da compreensão do uso que as mulheres fizeram da sua educação, traz uma contribuição relevante para o campo da Educação. Isto pela possibilidade de assim se poder analisar as relações sociais possíveis destas mesmas mulheres em Aracaju, a partir da formação escolar, condição para sua aparição no cenário público e nos ambientes de entretenimento da cidade, no início do século XX.

\section{O INICIAR DO SÉCULO XX}

No cenário e período analisados, merecem atenção as significativas mudanças no comportamento e no modo de vida das pessoas, decorrentes de um crescente processo de urbanização e do surgimento de espaços de sociabilização, que, impulsionados pela modernidade, desencadearam um fenômeno que Sevcenko (1998) chamou de "mobilização permanente". Essa mobilização significou um constante deslocamento dos indivíduos da cena privada para a pública.

No início do século XX houve um número expressivo de mulheres letradas que fizeram uso racional dos acessos aos espaços de convivência social, como os clubes de dança, as associações esportivas, os grêmios recreativos, os salões de festas e os cafés, dentre outros. Nesses ambientes faziam demonstrações de habilidades, talentos e da capacidade de crítica política e social, através de suas composições, fazendo com que sua participação fosse benquista e requisitada. 0 incentivo à presença feminina nesses espaços revelava 0 desejo de conferir ao ambiente uma dita leveza, ternura e beleza da mulher, além do interesse pela apreciação de suas práticas e de possibilitar o desfrute das benesses da vida moderna. 
Como paradoxo a esses argumentos, vemos que por muitos anos a educação feminina foi projetada no sentido de formar mulheres aptas a cumprir a missão de esposa, mãe e dona de casa, inculcando na sua formação as bases para cumprir, com efeito, aquilo que a sociedade imputou a esse gênero, como vocação e destino.

De acordo com Almeida (2004), no interior das províncias, as crianças aprendiam as primeiras letras juntas e depois o ensino tornava-se diferenciado, ou seja, os meninos continuavam os estudos a fim de se prepararem para tornarem-se homens de sociedade, e as meninas findavam sua preparação na aptidão para os serviços domésticos e os cuidados que deveriam ter com marido e filhos. As que eram encaminhadas para os conventos também eram preparadas para o casamento e lá aprendiam história sagrada, bordado, culinária, cuidados do lar, escrever, ler, contar e um pouco de latim, para acompanhar as missas. Onde quer que fosse o vilarejo, fazenda, casa ou convento, a instrução necessária para a mulher se resumia em rudimentos de leitura, escrita, princípios religiosos, economia doméstica e trabalhos manuais.

Almeida (2004) assevera que, terminada a instrução da mulher, sua responsabilidade não deveria se estender para fora do seu lar, porém, isso seria aceitável se fosse para cuidar de alguém ou ajudar em um parto. Essas atividades eram admissíveis, se fossem realizadas como forma de doação e presteza, no entanto, proibidas enquanto trabalho assalariado.

Ainda que os primeiros anos republicanos despertassem o desejo de liberdade nos indivíduos, refletidos em ações de emancipação humana, nos mais diversos setores sociais, a resistência a essas possibilidades ao público feminino estava muito presente, enraizada nos padrões culturais do século XIX e mesmo no início do XX. O lema republicano de liberdade e progresso, não visava à independência social da mulher, menos ainda se isso ameaçasse romper com o poder patronal, que as mantinha submissas às regras de conduta familiar e social.

\section{A POSIÇÃO DA MULHER NO COMEÇO DO SÉCULO XX EM ARACAJU}

O deslocamento da mulher do lar para o público foi uma conquista que aos poucos se firmou através de práticas de resistência, configurando-se como uma revolução passiva, na qual, dentro das normas que eram socialmente aceitas, as mulheres buscaram estrategicamente se posicionar nos espaços projetados para seu convívio e sua sociabilidade.

\footnotetext{
A identidade feminina, resguardada entre vários segmentos sociais, era definida numa moldura cultural em que valores, normas, expectativas, imagens, regras, conceitos e preconceitos compunham o arcabouço social e determinavam os hábitos e costumes. Das mulheres esperava-se permanência no espaço doméstico, recato, submissão, o acatamento da maternidade como a mais elevada aspiração. Dos homens, a atuação no espaço público, no mundo do trabalho, na política, o exercício da liberdade, inclusive sexual, a incorporação dos atributos de proteção e autoridade (ALMEIDA, 2004, p. 73).
}

O século XX foi saudado por um cenário de manifestações femininas, donde emergiram movimentos pela liberação, pelo reconhecimento do deslocamento da sua posição na sociedade, do espaço privado e restrito do seu lar, para outras esferas, rompendo com a mentalidade construída por séculos, que subordinava a mulher ao homem e ao lar.

Para Taranto (2011), a formação da mulher é pensada em vista do lugar que the é reservado em um dado período, e o que se chama de natureza é uma mistificação engenhosa, 
produto de uma construção social, por meio de condicionamentos educativos e de restrições legais.

[...] os senhores das mulheres querem mais que a obediência, por isso desviaram em proveito de seu desígnio toda a educação. Todas as mulheres são criadas desde a infância na crença que o ideal de seu caráter é totalmente contrário àquele do homem; elas são instruídas a não querer por elas próprias, a não se conduzir segundo sua vontade, mas a se submeter e a ceder à vontade dos outros (MILL', 1992, p. 13 apud TARANTO, 2011, p. 91).

Por muito tempo, a condição feminina, em termos de educação e ocupação de espaço público, esteve condicionada ao modo pelo qual a sociedade definia e estruturava os padrões de comportamentos, de hábitos e de costumes que regulavam onde e como os indivíduos deveriam estar.

No início do século XX, em algumas localidades, como exemplo a cidade de Aracaju, surgiram clubes recreativos, projetados pela elite e destinados a uma parcela diminuta da sociedade. Logicamente, as mulheres que tiveram acesso a esses ambientes eram consideradas personalidades intelectuais do cenário social sergipano. Essas mulheres também se destacavam pela ocupação de outros espaços, devido ao acesso a uma educação diferenciada, a uma cultura letrada e, também, pelo fato de estarem engajadas em movimentos sociais, principalmente os das lutas feministas em prol da emancipação da mulher.

Percebemos essa elite, a partir do entendimento de Bourdieu (1999), como um grupo restrito de indivíduos que acumulou um capital simbólico, fosse ele cultural, econômico, religioso, político, militar, social ou de outra natureza. Tal condição permite o reconhecimento entre os pares, dando-lhes um status privilegiado, com funções de mando, de direção, de orientação ou representação.

Para a compreensão do significado de "representações", nos apropriamos de Chartier (2002, p. 73), que afirma que 0 :

[...] trabalho de classificação e de recorte que produz as configurações intelectuais múltiplas pelas quais a realidade é contraditoriamente construída pelos diferentes grupos que compõem uma sociedade; em seguida, as práticas que visam a fazer reconhecer uma identidade social, a exibir uma maneira própria de estar no mundo, a significar simbolicamente um estatuto e uma posição; enfim, as formas institucionalizadas e objetivadas graças às quais 'representantes' (instâncias coletivas ou indivíduos singulares) marcam de modo visível e perpetuada existência do grupo, da comunidade ou da classe.

Dessa forma, percebemos as representações, tais quais Chartier (2002) as apresenta, como práticas que se moldam em um determinado espaço, construídas a partir de um ideal coletivo ou individual, que por sua vez formam identidades sociais e, portanto, coletivas, resultantes das relações de forças impostas por aqueles que têm o poder de classificar, de nomear e definir padrões, normas, modelos sociais, culturais, políticos e educacionais.

[...] por um lado, as representações coletivas que incorporam nos indivíduos as divisões do mundo social e organizam os esquemas de percepção a partir dos quais eles classificam, julgam e agem; por outro, as formas de exibição e de estilização da identidade que pretendem ver reconhecida; enfim, a delegação a representantes (indivíduos particulares, instituições, instâncias abstratas) da coerência e da estabilidade da identidade assim afirmada (CHARTIER, 2002, p. 11).

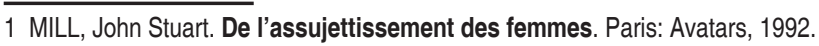


É importante salientar que, nas representações, a forma de apropriação dos valores que são repassados, para que sejam (re)produzidos, não é sempre acomodada de forma passiva, pois, para Chartier (2002), seja em forma de submissão, seja em forma resistência, os indivíduos constroem suas próprias representações das estratégias simbólicas que determinam as posições.

Algumas representações moldaram-se em torno do desejo de grupos de indivíduos que tinham o interesse em serem reconhecidos como uma elite intelectual. Essa percepção já fora apontada por alguns pesquisadores, como no caso do estudo realizado por Silva (2006), sobre a formação dos intelectuais em Sergipe durante o Império. A autora preferiu chamá-los de intelligentsia, para fazer alusão a pessoas que tiveram formação acadêmica e que exerceram funções legitimadoras de seu poder.

Burke (2003, p. 26) afirma que a palavra "[...] intelligentsia foi cunhada para referir-se aos homens de letras que não queriam ou conseguiam encontrar posições na burocracia". Ao tratar da denominação dos indivíduos descendentes da intelligentsia do século XIX, o autor opta por chamá-los de "letrados", e emprega o termo "[...] para descrever grupos sociais, cujos membros se consideravam 'homens de saber' (docti, eruditi, savants, Gelehrten), ou 'homens de letras' (literati, hommes de lettres)".

No segundo capítulo da sua obra (2003, p 26), Burke, ao propor discutir um ensaio sociológico apresentado como "O papel social do homem de saber", chama atenção para a necessidade de levantar questões sobre as mulheres de saber, em um período no qual os homens referiam-se a si mesmos como cidadãos da "República das Letras" (Republica litteraria), momento no qual as mulheres "estavam mais ou menos 'excluídas' da busca do saber".

Conforme Burke (2003), havia algumas mulheres letradas e instruídas que ao longo de períodos tiveram sua produção intelectual conhecida, entretanto, elas não participavam da República das Letras nos mesmos termos que os homens, e, caso elas tentassem entrar no círculo dos humanistas, podiam ser repelidas. $O$ autor também ressalta que algumas mulheres fizeram parte da Revolução Científica e do lluminismo, entretanto, sua posição diante do contexto também era marginal.

No caso deste estudo, as mulheres aqui tratadas despontaram no cenário intelectual e cultural sergipano, tendo, por isso, acesso aos espaços de entretenimento no início do século $X X$, compondo uma geração que foi considerada letrada e, por conseguinte, integrante de uma elite no cenário social de Sergipe.

Essas elites, compreendidas por Sirinelli (1997, p. 274.) como "elites culturais", definemse, especialmente, pelo seu poder de influência, isto é, de ressonância e de amplificação, repercutidas na sociedade pela legitimidade das tomadas de decisão e ações relevantes em matéria cultural. $\mathrm{O}$ autor utiliza alguns critérios para definir o limiar de pertencimento dos indivíduos a essas elites. Ao propor uma definição empírica de um homem de cultura, Sirinelli (1997) classificou os indivíduos em duas categorias: os criadores e os mediadores.

Para Sirinelli (1997), entre as elites de criação estão os sujeitos que, através de suas experiências, criam/fomentam/representam eventos e práticas culturais, participam na criação artística e literária ou no progresso do saber. Nesse grupo incluem-se os indivíduos que gozam de notoriedade, reconhecimento pelos seus pares e extensão das suas obras. Já os mediadores culturais são os que contribuem para difundir e vulgarizar os conhecimentos da 
criação e do saber. Destacam-se pela capacidade de ressonância e amplificação, ou seja, pelo poder de influência.

O reconhecimento, tanto dos criadores como dos mediadores culturais, é conformado, em um primeiro momento, de forma endógena. Isso ocorre por conta das resistências e pressões que cada grupo encontra ao tentar legitimar seus pensamentos, suas produções, percepções e formas de dissipação dos saberes. Uma vez que estes tenham sido admitidos no interior de cada grupo, por meio dos méritos atribuídos e aceitos entre seus pares, que, por sua vez, também são seus concorrentes, exteriorizam seus dispositivos para que sejam refletidos e aceitos na sociedade de forma qualificada e, se possível, institucionalizada.

Essa simbologia de identidade intelectual ligada ao domínio das letras e as ideias de pertencimento a grupos de elites culturais, assim como a possibilidade de inserção no âmbito público, seja pelo poder de ressonância, seja pela produção cultural, permitiu que muitas mulheres sergipanas se enquadrassem em grupos de intelectuais do período republicano.

Essa condição tornou-se possível devido ao reconhecimento via formação. Neste ponto, a escola desempenhou um papel fundamental, por garantir e legitimar a competência, materializada pela posse do diploma, fator essencial na repercussão da imagem social, principalmente por possibilitar a proximidade com o mundo intelectual masculino e com a condição de mulher letrada. Por conseguinte, puderam fazer uso dessa posição para a ocupação feminina de espaços públicos de visibilidade.

\section{CLUB SPORTIVO FEMININO COMO ESPAÇO DE SOCIABILIDADE}

Burke (2002) identifica os clubes como instituições a meio caminho entre o mundo privado da família e a esfera pública da sociedade civil, ou seja, um espaço de circulação social. Neste sentido, os clubes e os espaços de eventos festivos funcionaram como o lugar propício para fomentar as relações de sociabilidade, ambientes dos quais as mulheres letradas de Aracaju, pertencentes à intelligentsia sergipana, fizeram uso para reafirmar mais um passo, rumo à aparição e ao desfrute da vida pública.

O estudo desenvolvido por Pereira (2010) retrata a vida dos clubes dançantes, no subúrbio do Rio de Janeiro na Primeira República, revelando o gosto dos moradores dos bairros pelos bailes promovidos pelas agremiações, fato que despertava o interesse pelo associativismo dançante. $\mathrm{O}$ autor mostra a centralidade que as festas com dança assumiram no cotidiano das pessoas, e evidenciou a emergência de inúmeros espaços dançantes no subúrbio carioca, que se organizavam sob a justificativa de promover festejos diversos para os associados. A proposta era oferecer lazer e sociabilidade, com a promoção de bailes, na condição de que estes fossem morais e honestos.

De acordo com Pereira (2010, p. 278-279), os cronistas do Rio de Janeiro viam esse movimento dos clubes dançantes com estranhamento, pois achavam contraditório que os moradores do subúrbio, apesar de viverem com privações, desfrutassem das festas e tentassem se "igualar à alegria própria dos que dançavam nos salões elegantes da cidade". Este dado nos traz a percepção de que as festas que envolviam dança eram um fenômeno expressivo e característico de um público dotado de uma condição social privilegiada, mas que também foi apropriado por outras camadas sociais, que o ressignificaram, fazendo dele um espaço atrativo e intenso. 
Pereira (2010, p. 277) caracteriza esse entusiasmo como uma "febre dançante", a qual se mostrava como um poderoso fenômeno social no Rio de Janeiro do começo do século XX.

Ao se reunirem em associações recreativas, participarem de festas e aproveitarem seu tempo livre para buscar na dança e na música um meio privilegiado de diversão, muitos outros sujeitos mostravam, desde o final do século XIX, a centralidade do ritmo, da dança, da música e da festa para suas próprias experiências. Para além das fronteiras do mundo letrado, é preciso, por isso, buscar o modo pelo qual tais tradições foram construídas também a partir de experiências, sonhos e aspirações de sujeitos que não tinham na escrita sua forma privilegiada de expressão (PEREIRA, 2010, p. 283-284).

Para melhor compreender o significado dos espaços e os sentidos destinados aos lugares, Frago e Escolano (1998) nos esclarecem que a construção destes é dotada de intencionalidades:

[...] o espaço jamais é neutro: em vez disso, ele carrega, em sua configuração como território e lugar, signos, símbolos e vestígios da condição e das relações sociais de e entre aqueles que o habitam. $O$ espaço comunica; mostra, a quem sabe ler, 0 emprego que o ser humano faz dele mesmo (FRAGO; ESCOLANO, 1998, p. 64).

[...] todo espaço é um lugar percebido. A percepção é um processo cultural. Por isso, não percebemos espaços, senão lugares, isso é, espaços elaborados, construídos (FRAGO; ESCOLANO, 1998, p. 78).

Tendo visto as configurações do espaço da mulher na sociedade e nos cenários de diversão, dentre estes os bailes dançantes, além de analisarmos suas possibilidades educativas e de inserção num determinado estrato social, buscamos reconstruir o retrato histórico em torno da mulher imersa na cena urbana de entretenimento. Assim, tentamos compreender a projeção do espaço e a criação dos lugares pensados para fomentar a sociabilidade, como grêmios literários, associações recreativas, salões palacianos, clubes, dentre outros, que intensificaram as vivências culturais femininas, especificamente em Aracaju.

De acordo com o estudo realizado por Almeida (2004), na capital sergipana, os bailes dançantes ganharam força e expressividade através das festas promovidas pelo Club Sportivo Feminino (CSF), uma agremiação para mulheres criada no ano 1919, com a finalidade de propiciar práticas esportivas e festas dançantes para a elite aracajuana, constituída por homens e mulheres de posse de diploma e que, por isso, eram considerados como integrantes da intelligentsia local no início do século XX.

A elite aracajuana classificava os eventos sociais dançantes que promoviam como festas lítero-dançantes, ou saraus lítero-dançantes. Os termos alocavam os indivíduos em uma posição de distinção social, através da qual se reconheciam como intelectuais, artistas e indivíduos "de escola":

Uma festa brilhante. 0 victorioso Club Sportivo Feminino levará a efeito, amanhan a noite no salão superior da bilbliotheca pública, com uma esplendida festa lítero-dançante musical, cujo preço do ingresso é diminutíssimo. Tomarão parte os seguintes intellectuais e artistas, todos de escola aracajuana: Dr. Edlson Ribeiro, Dr. Álvaro Silva, Godofredo Diniz, acadêmico Clodomir Silva, professor Artur Fortes, Candoca Jorge, Dr. Porto Carrero, Laura Fernandes, Laura Rocha e Joaquim Fernandes [...] (CORREIO DE ARACAJU, 30 nov. 1923, p.2)2.

2 Nos trechos extraídos dos jornais, optamos por manter a grafia de época. Nas referências dos jornais citados, não são encontrados autores e nem títulos das matérias. 
Associar as atividades intelectuais e a cultura das letras aos eventos festivos e dançantes era uma prática que marcava a essência dos clubes recreativos de elite, que surgiram no início do século XX. Nos eventos do Club Sportivo Feminino eram frequentes os bailes, os saraus, as retretas e uma diversidade de festas que carregavam nomes como Soiré, Pris Wide, dentre outros, onde se entoavam os ritmos musicais, que variavam dos clássicos aos modernos e que eram intercalados com recitais literários, apresentações artísticas e culturais.

Mais uma noite admirável, plena do riso feminino de nossas lindas girls e da satisfação de nossos rapazes, nos proporcionará, hoje, a sympathica e bem organizada agremiação que é o Club Sportivo Feminino. Estará, assim, hoje, sorridente de luz o vasto salão da Bibliotheca Pública do Estado, onde inúmeros pares voltearão, delirantes, ao som de escolhidos trechos musicais de uma bem confeccionada orchestra (SERGIPE JORNAL, 14 jun. 1924, p. 2).

Da illustre directoria do Club Sportivo Feminino, acabamos de receber um delicado convite para o próximo sarau dançante que effectuará no próximo domingo, 19h, 26 do corrente, em comemoração ao seu aniversário de fundação. A julgar pelas anteriores, é de crer, que a próxima a ser realizada tenha grande afluência do nosso mundo social e do que Sergipe tem de mais chic (SERGIPE JORNAL, 22 set.1925, p. 2).

Nas festas pairava uma atmosfera de alegria e prazer, que impulsionava os indivíduos a embalarem o corpo ao frenesi do movimento dançante, com a tranquilidade e satisfação de estarem desfrutando de momentos de partilha cultural, no universo da elite letrada de Aracaju. Esses eventos não só agregavam, como manifestavam nos indivíduos o sentimento de pertencimento ao lugar e de acompanhamento da modernidade, refletido na percepção de usufruírem das "afluências do nosso mundo social" e do que se podia considerar como "chic", moderno.

Annunciado como estava, realizou-se antehontem, no salão da Bibliotheca Pública, a festa lítero-musical dançante do victorioso Club Sportivo Feminino, a mais chic agremiação desportiva de Sergipe, cujas festas se revestem sempre ao máximo brilhantismo, parecendo, por esta razão, todas iguais. Entretanto temos a impressão de que a última foi melhor. Foi uma noite de arte, mas de verdadeira arte ... (CORREIO DE ARACAJU, 2 dez. 1923, p. 2).

Os jornais descreviam as festas dançantes do Club Sportivo Feminino como eventos esplêndidos, brilhantes, requintados e envoltos em certo glamour, demonstrando o quanto era elaborado e seletivo o ambiente, com uma programação artística e literária digna dos intelectuais e da apreciação de uma pequena parcela da sociedade:

[...] Porto Carrero em evidência com o seu viollino conhecedor da arte de Paganini, o ilustre musicista executa magistralmente $<<$ Doris bébe $>$ e qual seria a criança que não adormecesse aquelles acordes. Godofredo Diniz, com dicção eloquente e arrebatada, <<entretém>> diálogo psicológico e ao mesmo tempo humorístico com uma senhorinha, prometendo a Delegacia fiscal para sede do Club Sportivo Feminino»>... quando fosse deputado. Artur Fortes, empolgante e brando, lê três esplendidas madrigaes por elle traduzidos de poeta espanhol. Leyda Régis, chistosa e satírica, faz suave e agudo comentário sobre $0<<$ Sereno $>$. Cecinha Mello, com sua arte de falar reconhecida, diz excellentes versos. Dr. Porto Carrero volta a deliciar o auditório com o seu violino mágico, tocando <<Serenata Coquette > $>$. Joaquim Fernandes, com voz sonoríssima, canta a canção sentimental 《< Povera mama»>. Clodomir Silva, o irresistível, obriga a assistência à hilaridade com a sua chronica folklorista. Candoca Jorge, sentimental e expressiva, com explendida voz canta 《< Los ojos negros >>. Laura Rocha caricatura a giz Dr. Porto Carrero, senhorinha Zuzu Fernandes e Clodomir 
Silva. Os acompanhamentos a piano foram todos feitos impecavelmente pela senhorinha Laura Fernandes. A parte lítero-musical foi portanto, de magnífico e inexcedível êxito. Não houve ponto fraco. Seguiu-se a parte dançante. A banda de música da polícia desafiava os circulantes, e o piano de Caçula Santos estava irresistível (CORREIO DE ARACAJU, 2 dez. 1923, p. 2).

Nas festas dançantes do Club Sportivo Feminino, percebe-se que o lugar do baile ampliava-se para além da dança, tomando uma configuração de palco de expressividades artísticas, culturais e intelectuais. Estas eram representadas de diversas maneiras, com a participação de vários personagens da sociedade local.

A ação destas pessoas se dava a partir de suas habilidades e talentos, sendo os eventos um espaço de demonstração destes. Podemos citar várias figuras que participavam desses momentos. Laura Rocha demonstrava sua habilidade com a pintura e o desenho, caricaturando a giz os convidados da festa. Outras manifestações emergiam com exibições de talentos musicais reveladas pelo canto de Joaquim Fernandes e Candoca Jorge, e pelo domínio dos instrumentos, a exemplo do Dr. Porto Carrero com o violino e Laura Fernandes com o piano. Existiam também demonstrações de domínio das letras e línguas estrangeiras de Artur Fortes; as diversas declamações de autoria própria, como a crônica folclorista de Clodomir Sillva, os versos de Cecinha Melo e poesia satírica sobre "o Sereno" de Leyda Régis, que fazia referência, em suas palavras, àqueles que estavam do lado de fora, longe do calor dos bailes palacianos; além de relatos humorísticos de percepções acerca dos lugares ocupados por cada indivíduo na sociedade. 0 ambiente também criava aproximações, instigava o flerte, oportunizava a exposição da beleza e da juventude, além de propiciar momentos oportunos para se conseguir um bom partido para o casamento.

Os espaços dos eventos formavam uma configuração propícia para expressar o alcance das mulheres ao mundo da cultura, principalmente em se tratando do poder de produção literária, da capacidade de expor com clareza, lógica e elegância, as produções intelectuais femininas, além das suas competências para organizar e gerenciar os eventos.

Os jornais frequentemente faziam referência ao prestígio e à boa reputação das mulheres que participavam dos eventos festivos promovidos pelo Club Sportivo Feminino, principalmente pelo parentesco com homens que exerciam função de relevante importância na esfera pública. Tal parentesco conferia-lhes um status social privilegiado, por fazerem parte de um universo cultural valorizado.

Os indivíduos que usufruíam do entretenimento e do lazer proposto pelos clubes de elite conviviam em um ambiente que aspirava à formação intelectual de suas filhas, esposas e parentes, que seriam as detentoras de diplomas de formação superior, oferecendo-lhes 0 acesso ao mundo civilizado e moderno, através da valorização da educação e, por conseguinte, da sua atuação profissional, que foi possível principalmente àquelas menos abastadas, pelas relações sociais que os parentes mantinham.

Outro fator importante que introduziu essas mulheres no campo social foi a condição conjuntural na qual se encontrava o país. Vivia-se um período de expansão do mercado de trabalho, com uma maior disponibilidade de cargos que exigiam a especialização em nível superior. Assim, as mulheres que tinham posse de diploma puderam atuar como profissionais, conquistando o reconhecimento e a visibilidade no âmbito social. 
Muitos foram os ambientes pensados e bem elaborados pelas mulheres e entusiastas da emancipação feminina para promover canais possíveis de acesso das mulheres ao universo das elites culturais. $O$ próprio CSF funcionou como uma instituição que fomentava espaços de convivência e sociabilidade. Tal fato é perceptível ao analisarmos as configurações estabelecidas nas festas dançantes organizadas pela agremiação. As festividades eram veiculadas pelos jornais que circularam em Aracaju, que pontuavam o brilho dos momentos e os grupos de elites que deles participavam.

Os eventos promovidos pelo clube eram sempre noticiados como festas esplêndidas da sociedade sergipana. Embora as notícias parecessem convidativas, pelo baixo preço do ingresso, os jornais pontuavam o lugar no qual aconteceriam os bailes dançantes promovidos pelo Clube Sportivo Feminino: os salões do Clube dos Diários e do Recreio Clube, que eram os grêmios dançantes mais requintados da cidade, o salão do Palácio do Governo e o salão nobre da Biblioteca Pública. Isso nos permite inferir o quanto o espaço era delimitado e impunha condições de acesso, exigindo, além do valor em espécie para entrada, trajes "adequados" para os bailes. Assim, embora as manchetes instigassem o convite ao desejo de pertencimento e a possibilidade de compartilhar espaços privilegiados, nos quais estariam presentes intelectuais e indivíduos de status cultural notório, a acessibilidade era restrita a grupos minoritários da sociedade aracajuana.

A imprensa aracajuana recebia inúmeros convites para participar e, logicamente, fazer a cobertura desses eventos. $O$ ato em si era interessado, o jornal funcionava como um instrumento eficaz, legítimo e de grande poder de amplificação social, fazendo ressoar as diversas formas de manifestações femininas nesses espaços, pois as festas do Club Sportivo Feminino firmavamse como momentos oportunos para expor os talentos e as criações culturais das mulheres. Com isso, em edições consecutivas, os jornais pontuavam com detalhes as configurações das festas. As manchetes acompanhavam as atividades, relatando a participação e desenvoltura, assim como as temáticas artísticas apresentadas pelos protagonistas.

Os jornais frequentemente faziam referência ao prestígio e à boa reputação das mulheres do Club Sportivo Feminino, isto por conta do parentesco destas com homens que exerciam funções de relevante importância na esfera pública. Essa foi uma outra estratégia usada para expor ao público a presença feminina de forma legitima, por conferir-Ihes um status social privilegiado, fazendo parte de um universo valorizado, um fator de distinção de classe.

\section{CONCLUSÕES}

A nossa parcela de contribuição para uma parte da história que privilegia a mulher na trama do seu cotidiano buscou conhecer a singularidade da aparição pública feminina em clubes dançantes na cidade de Aracaju no início do século XX, condição esta possível devido às representações construídas em torno de grupos de elites culturais. Estas representações, mediadas pelo grau de instrução que tinham, ofereciam às mulheres autonomia, respeito, legitimidade e reconhecimento da condição de letradas, ainda que em forma de resistências recíprocas entre as práticas femininas e a dominação masculina.

As mulheres que tiveram acesso aos espaços de sociabilidade criados pelos grupos de elites culturais já se destacavam pela ocupação de outros cenários de visibilidade pública, 
tinham acesso à literatura e estavam engajadas em diversas atividades institucionalizadas no âmbito religioso, filantrópico, educacional e artístico, dentre outros.

Eram pessoas que conviviam em um ambiente que aspirava à formação intelectual de mulheres, que seriam as detentoras de diplomas de formação superior, filhas, esposas e parentes próximos de homens letrados e de notório status social. Esses homens possibilitaram a essas mulheres o acesso ao mundo civilizado e moderno através da valorização da educação e, por conseguinte, do investimento na sua atuação profissional, que foi possível principalmente às menos abastadas.

Com isto, afirmamos que a investigação de alguns aspectos da dinâmica de grupos que trabalharam no sentido de propiciar às mulheres a participação efetiva como protagonistas dos processos sociais funcionou como uma tentativa de romper com as regularidades do cotidiano, que estavam estabelecidas como lugares historicamente reservados ao gênero masculino.

A partir deste entendimento percebemos que os bailes dançantes, onde pulsavam as manifestações dos clubes recreativos em Aracaju nas primeiras décadas do século XX, funcionaram como criadores de espaços e lugares dotados de significados, ambientes pensados e projetados para constituir momentos de lazer, entretenimento e expressividade cultural e intelectual para algumas mulheres aracajuanas, sendo um espaço de sociabilidade possível ao momento histórico e à condição feminina na sociedade local.

\section{REFERÊNCIAS}

ALMEIDA, Marlaine Lopes de. Práticas esportivas em Aracaju no início do século: um estudo sobre a participação da mulher. 2004. 76 f. Monografia (Licenciatura em Educação Física) Departamento de Educação Física/Universidade Federal de Sergipe, São Cristóvão, 2004.

BOURDIEU, Pierre. A economia das trocas simbólicas. São Paulo: Perspectiva, 1999.

BURKE, Peter. Uma história social do conhecimento: de Gutenberg a Diderot. Rio de Janeiro: Jorge Zahar, 2003.

BURKE, Peter. História Social dos Clubes. Folha de São Paulo. São Paulo, 24 de fevereiro de 2002 p1-4.

BURKE, Peter. A escrita da História: novas perspectivas. São Paulo: UNESP, 1992.

CHARTIER, Roger. À beira da falésia: a história entre certezas e inquietude. Porto Alegre:

Editora da UFRGS, 2002.

CHARTIER, Roger. A história cultural: entre práticas e representações. Lisboa: Difel; Rio de Janeiro: Bertrand Brasil, 1990.

CORREIO DE ARACAJU, Aracaju, 2 dez. 1923, p 2.

CORREIO DE ARACAJU, Aracaju, 30 nov. 1923, p.2. 
FRAGO, Antonio Vinão; ESCOLANO, Augustin. Currículo, espaço e subjetividade: a arquitetura como programa. Rio de Janeiro: DP\&A, 1998.

PEREIRA, Leonardo. O Prazer das Morenas: bailes ritmos e identidades no Rio de Janeiro da

Primeira República. In: MARZANO, Andrea; MELO, Victor Andrade de. Vida Divertida: histórias do lazer no Rio de Janeiro (1830-1930). Rio de Janeiro: Apicuri, 2010. p.275-299.

SERGIPE JORNAL, Aracaju, 22. set. 1925, p. 2.

SERGIPE JORNAL, Aracaju, 14 jun, 1924, p.2.

SEVCENKO, Nicolau. Orfeu extático na Metrópole: São Paulo, sociedade e cultura nos frementes anos 20. São Paulo: Companhia das Letras, 1998.

SILVA, Eugênia Andrade Vieira. A formação intelectual da elite sergipana (18221889). 2004, 121f. Dissertação (Mestrado em Educação) - NPGED/UFS, São Cristóvão, 2006.

SIRINELLI, Jean-François. As Elites Culturais. In: RIOUX, Jean Pierre; SIRINELLI, JeanFrançois. Para uma História Cultual. Lisboa: Estampa, 1998. p 259 - 278.

TARANTO, Pascal. John Stuart Mill e a emancipação das mulheres como processo civilizatório. In: SILVA, Genildo Ferreira da. História e Civilização. Edufba: Salvador. 2011. p 81-99. 